\title{
Prospective Swiss pilot study of Endocuff-assisted colonoscopy in a screening population
}

Authors

Institutions
Mikael Sawatzki ${ }^{1}$, Christa Meyenberger ${ }^{1}$, Urs Albert Marbet ${ }^{2}$, Johannes Haarer ${ }^{1}$, Remus Frei ${ }^{1}$

${ }^{1}$ Division of Gastroenterology and Hepatology, Kantonsspital St. Gallen, Switzerland

${ }^{2}$ Division of Gastroenterology and Hepatology, Kantonsspital Uri, Switzerland submitted

26. November 2014

accepted after revision

24. December 2014

\section{Bibliography}

DOI http://dx.doi.org/

10.1055/s-0034-1391418

Published online: 27.2 .2015

Endosc Int Open 2015; 3: E236-

E239

(c) Georg Thieme Verlag KG

Stuttgart · New York

E-ISSN 2196-9736

\section{Corresponding author}

\section{Mikael Sawatzki, MD}

Gastroenterology/Hepatology Kantonsspital St. Gallen Rorschacherstrasse 95 CH-9007 St. Gallen Switzerland

Fax: +41-71-4946327

Mikael.sawatzki@kssg.ch
Background and study aims: The adenoma detection rate (ADR) is one of the quality measures in screening colonoscopy and is crucial for reducing colorectal cancer morbidity and mortality. Up to $25 \%$ of adenomas are missed during colonoscopy. Endocuff is an easy-to-use device that is attached like a cap to the distal tip of the colonoscope in order to optimize visualization behind the folds of the colon and increase the ADR. This is the first prospective study of Endocuff-assisted colonoscopy (EC) in a screening population with follow-up to determine the ADR and adverse events of EC. Patients and methods: We prospectively enrolled asymptomatic patients referred for screening colonoscopy during the 4-month study period. We documented the Boston Bowel Preparation Scale (BBPS) score, cecal intubation rate, polyp detection rate, ADR, number of advanced adenomas, and number of adverse events. Colonoscopies were performed by five board-certified gastroenterologists. During follow-up, the patients were called 4 to 12 weeks after EC.

\section{Introduction}

$\nabla$

The adenoma detection rate (ADR) is one of the quality measures in screening colonoscopy and is crucial for reducing colorectal cancer (CRC) morbidity and mortality. The ADR differs widely among populations, reaching approximately $21.7 \%$ in a large screening population [1]. Up to $25 \%$ of adenomas are missed during colonoscopy because of poor colon preparation and poor visualization behind the folds of the colon. Flat lesions in the right side of the colon can be particularly difficult to detect [2]. The ADR is inversely associated with the risk of interval CRC. The lower the ADR, the higher the risk of cancers after colonoscopy; each $1 \%$ increase in the ADR lowers the risk of interval cancers by $3 \%$ [3].

License terms

(ब)(1) $\ominus \circledast$
Several endoscopic innovations and devices have been developed to increase the ADR, with either
Results: A total of 104 EC procedures were performed. Cecal intubation was achieved in $99 \%$ of the patients, with a median intubation time of 6 minutes. The polyp detection rate and ADR in our study were $72 \%$ and $47 \%$, respectively, and $13.5 \%$ of the lesions were advanced adenomas. A significant number of adenomas were detected in the right side of the colon. Considering all the adenomas and hyperplastic polyps above the sigmoid, we recommended that nearly $60 \%$ of our patients repeat an endoscopic follow-up according to the existing Swiss guidelines. We noted no perforations or other serious adverse events, even in the patients with extensive diverticulosis.

Conclusions: EC is feasible with the most commonly available colonoscopes without severe adverse events. EC seems to be a safe and effective device for increasing the ADR, including small adenomas in the right side of the colon. Therefore, this technique may be recommended in the future to increase the ADR in a screening population.

limited benefit (e.g., visual enhancement technologies, cap) or high technical impact (Third Eye Retroscope; Avantis Medical Systems, Sunnyvale, California, USA; $330^{\circ}$ full-spectrum endoscopy) [4].

The Endocuff (Arc Medical Design, Leeds, United Kingdom) is a Conformité Européenne (CE)-certified and Food and Drug Administration (FDA)-approved device that is attached like a cap to the distal tip of the colonoscope ( $\bullet$ Fig. 1). The device has eight flexible branches arranged in two rows; these flatten the folds of the colon, pulling back the colonoscope in order to improve visibility behind the folds. The first retrospective analysis of 50 Endocuff-assisted colonoscopies (ECs) showed it to be a safe tool with a good procedural success rate in terms of cecal intubation and a promising ADR (34\%) [5]. The first randomized trial conducted in a mixed population found a significant- 

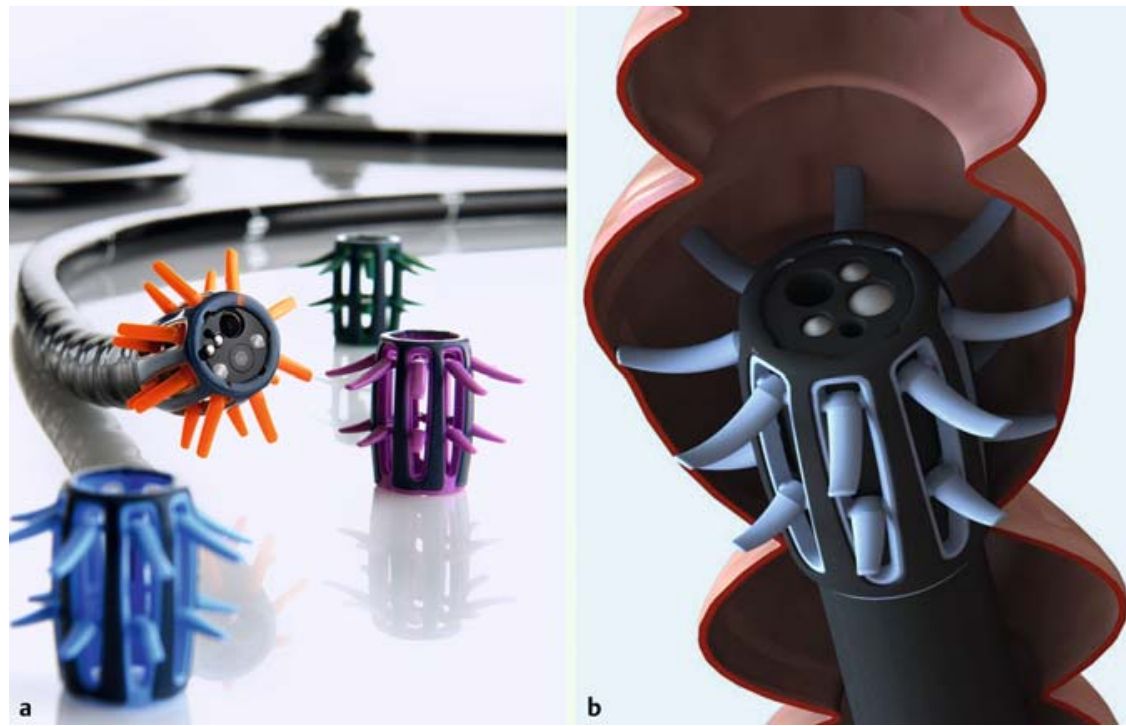

Fig. 1 Endocuff device used during screening for colorectal cancer. a The device is attached like a cap to the distal tip of the colonoscope. $\mathbf{b}$ The Endocuff is used to optimize visualization behind the folds of the colon and increase the adenoma detection rate. (Reproduced with permission of innoMedicus AG, Cham, Switzerland.).

ly higher ADR with the Endocuff than with standard colonoscopy (56\% vs. $42 \% ; P=0.001$ ) [6].

Our prospective study analyzed the feasibility, complication rate, and ADR of EC in a healthy screening population at three regional hospitals in Switzerland, with follow-up after EC to determine adverse events.

\section{Patients and methods \\ $\nabla$}

\section{Patients}

We prospectively enrolled 104 patients from outpatient clinics after referral for screening colonoscopy or follow-up of earlier polypectomy during the 4-month study period from February to June 2014. Written informed consent was obtained for EC. Informed consent and scientific data security were approved by the local ethics commission. The patients had no gastrointestinal symptoms and presented for screening. General exclusion criteria were referral because of gastrointestinal symptoms (e.g., abdominal pain, diarrhea, constipation, gastrointestinal or anal bleeding) and CRC in the history.

\section{Endoscopic procedures}

The patients underwent colonic lavage with a split dose of macrogol 3350 (Moviprep; Norgine, Amsterdam, the Netherlands) over 2 days. Colonoscopy was started with the patient in a left lateral position and under conscious propofol sedation. Carbon dioxide insufflation was used. After the sigmoid colon had been passed, most of the patients were examined in the supine position. Cecal intubation was documented on the basis of the appendix and, if possible, the terminal ileum. Before withdrawal, 10 to $20 \mathrm{mg}$ of intravenous butylscopolamine (Buscopan; Boehringer Ingelheim, Ingelheim, Germany) was administered to patients with no contraindications; two of the patients had contraindications: tachycardia, glaucoma.

We documented the following: Boston Bowel Preparation Scale (BBPS) score; time to cecal intubation; intubation of the terminal ileum; withdrawal time; polyp detection rate (PDR); ADR; number of advanced polyps (defined as tubular adenoma with high grade dysplasia, tubular adenoma with low grade dysplasia but $>9 \mathrm{~mm}$, and tubulovillous adenoma); grade of diverticulosis; and adverse events with a follow-up of 4 to 12 weeks during which the patients were called and interviewed.

The recorded measurements of the polyps are histopathologic descriptions. A total of 104 ECs were performed by five boardcertified gastroenterologists. Two endoscopists had performed a minimum of 5000 colonoscopies, two a minimum of 2500 , and one a minimum of 1000 colonoscopies before the study. We used CF-H180, CF-Q180AI, and PCF-Q180 colonoscopes (Olympus, Tokyo, Japan). Technical details were described previously $[5,6]$. The procedure time began with insertion of the colonoscope, included therapeutic interventions, and ended with removal of the endoscope. Follow-up consisted of calling the patients 4 to 12 weeks after EC and interviewing them about abdominal pain or rectal bleeding; required medical investigations were conducted by the general practitioner or during hospital admittance.

\section{Results \\ $\nabla$}

\section{Patient characteristics}

The patients' characteristics are shown in $\square$ Table 1. A total of 17 patients were younger than 50 years of age, including 14 with first-degree relatives who had CRC and 3 with carcinophobia. A total of 19 patients were older than 69 years of age and had a life expectancy of life of more than 10 years. A total of 88 patients presented for screening ( $85 \%$ ), and 16 patients presented for follow-up after earlier polypectomy (15\%). One-third of the patients had a first-degree relative with CRC. During screening colonoscopy, we found that $44 \%$ of the patients had diverticulosis, and 7 cases were extensive $(n=3$ at the sigmoid colon and $n=4$ with pan-diverticulosis).

\section{Colonoscopy characteristics}

Cecal intubation with EC was achieved in $99 \%$ of the procedures with a mean intubation time of 6 minutes (range 2-21 minutes). In one patient with severe diverticulosis, the sigmoid colon could be passed only without EC (PCF colonoscope). No polyps were detected in this patient. Ileal intubation was achieved in $64 \%$ of patients but was not forced in those without an indication for ileal intubation. Bowel preparation was very good in most cases, with a mean BBPS score of 8. Before withdrawal, butylscopolamine 
Table 1 Characteristics of the study patients undergoing screening for colorectal cancer with the Endocuff device.

\begin{tabular}{|lc|}
\hline Patients, $\mathrm{n}$ & 104 \\
\hline Age, mean (range), y & $59(33-80)$ \\
\hline Males, $\mathrm{n}(\%)$ & $57(54.8)$ \\
\hline Screening, $\mathrm{n}(\%)$ & $88(84.6)$ \\
\hline Polyp follow-up, $\mathrm{n}(\%)$ & $16(15.4)$ \\
\hline First-degree relatives with colorectal cancer, $\mathrm{n}(\%)$ & $32(30.7)$ \\
\hline Diverticulosis, $\mathrm{n}(\%)$ & $46(44)$ \\
\hline Severe diverticulosis, $\mathrm{n}(\%)$ & $7(6.7)$ \\
\hline
\end{tabular}

Table 2 Details of the Endocuff-assisted colonoscopy procedure in a screening population.

\begin{tabular}{|lc|}
\hline Cecal intubation, $\mathrm{n}(\%)$ & $103(99)$ \\
\hline Cecal intubation time, mean (range), min & $6(2-21)$ \\
\hline lleal intubation, $\mathrm{n}(\%)$ & $67(64.4)$ \\
\hline Withdrawal time without interventions, mean (range), min & $11(5-32)$ \\
\hline Boston Bowel Preparation Scale score, mean (range) & $8(6-9)$ \\
\hline Butylscopolamine before withdrawal, $\mathrm{n}(\%)$ & $100(96)$ \\
\hline Procedure time with interventions, mean (range), min & $26(10-122)$ \\
\hline
\end{tabular}

Table 3 Detection rates in a screening population undergoing Endocuffassisted colonoscopy.

\begin{tabular}{|c|c|}
\hline Polyp detection rate, $\mathrm{n}(\%)$ & $75(72)$ \\
\hline Adenoma detection rate, $\mathrm{n}(\%)$ & $49(47)$ \\
\hline Advanced adenomas, n (\%) & $14(13.5)$ \\
\hline $\begin{array}{l}\text { Adenoma detection rate with consideration of hyperplastic } \\
\text { polyps above sigmoid colon, } \mathrm{n}(\%)\end{array}$ & $60(57.7)$ \\
\hline
\end{tabular}

Table 4 Characteristics of advanced adenomas in a screening population undergoing Endocuff-assisted colonoscopy.

\begin{tabular}{|lr|}
\hline Adenomas $10 \mathrm{~mm}$ or greater, $\mathrm{n}$ & 11 \\
\hline Tubulovillous adenomas & 2 \\
\hline Neuroendocrine carcinoid & 1 \\
\hline
\end{tabular}

Table 5 Mild adverse events after Endocuff-assisted colonoscopy in a screening population.

\begin{tabular}{|ll|}
\hline Mild adverse events, $\mathbf{n}(\%)$ & $\mathbf{5}(\mathbf{4 . 8 )}$ \\
\hline Bleeding (after polypectomy), $\mathrm{n}(\%)$ & $2(1.9)$ \\
\hline Abdominal pain (with diverticulosis), $\mathrm{n}(\%)$ & $2(1.9)$ \\
\hline Anal fissure, $\mathrm{n}(\%)$ & $1(0.96)$ \\
\hline
\end{tabular}

(10-20 mg) was administered intravenously to $96 \%$ of the patients. The mean withdrawal time was 11 minutes. The mean procedure time with polyp removal and, if necessary, clip application (because of bleeding or to prevent bleeding) was 26 minutes. The polyp retrieval rate was higher than the $90 \%$ recommended by the European Society of Gastrointestinal Endoscopy [7]. Retroflexion in the rectum was easily performed with EC but not evaluated. The colonoscopy details are shown in $\bullet$ Table 2 .

\section{Polyp and adenoma detection rates}

In 75 patients, at least one polyp was detected and removed (72\%). We detected 293 polyps in 104 patients, for a mean of 3.9 polyps per patient with dimensions of 2 to $30 \mathrm{~mm}$. The ADR with EC was $47 \%$ (49 of 104 patients). When hyperplastic polyps above the sigmoid colon $(\mathrm{n}=11)$ were considered in addition to the adenomas with dysplasia, the detection rate was $57.7 \%$ ( Table 3 ).
In 20 of the 49 patients in whom an adenoma was detected, the adenoma was in the right side of the colon (colon ascendens), and in 12 patients the adenoma was $5 \mathrm{~mm}$ or smaller. In our study population, advanced adenomas ( Table 4$)$ were detected and removed in $13.5 \%$ of the patients. We found no difference in the ADR when EC in the morning was compared with EC in the afternoon. No significant difference was found in the ADRs of the endoscopists. The detection rates are shown in 0 Table 3.

\section{Adverse events}

We noted no severe adverse events, including perforations. Insignificant mucosal scratches were not noted during endoscopy. The mild adverse effects (5\%) are summarized in Table 5. Follow-up was performed by calling the patients 4 to 12 weeks after EC. We contacted 102 of the patients (98\%). Two patients reported brief, transient rectal bleeding after rectal polypectomy but required no medical consultation. One patient with mild diverticulosis of the sigmoid colon reported transient abdominal pain 1 week after EC with two polypectomies. The patient with severe diverticulosis of the sigmoid colon that could be passed only without the Endocuff developed transient abdominal pain 2 days after the endoscopy. This case of possible post-interventional diverticulitis was treated successfully with antibiotics by the patient's general practitioner (follow-up 12 weeks). One patient had a small anal fissure after EC, which was treated effectively by stool softening.

\section{Discussion}

The ADR is crucial for reducing CRC morbidity and mortality, and EC seems to be effective for improving the ADR. This is the first prospective study of EC in a screening population with followup showing an excellent ADR of $47 \%$ and a PDR of $72 \%$ without significant adverse events. The feasibility and sufficiency of ADR were demonstrated previously in a mixed study population $[5,6]$. The first retrospective analysis of 50 ECs reported good procedural success in terms of cecal intubation, with a promising ADR of $41 \%$ in a screening population subgroup comprising only 17 patients and improved tip control, particularly for polypectomy [5]. The first prospective study comparing standard colonoscopy and EC demonstrated a significantly higher PDR [6], but the evaluated population also included symptomatic patients. The ADR reached $36 \%$ with EC vs. $28 \%$ with standard colonoscopy in 498 patients. A strength of our study was the "healthy" study population undergoing screening, with an optimal mean age of 59 years. The cecal intubation rate of $99 \%$ is an excellent result with EC, and the time to cecal intubation is comparable with that of a previous study [5]. With excellent bowel preparation, the average withdrawal time in our study was 11 minutes. The optimal withdrawal time is considered to be 10 minutes. [8]. The good ADR in the right side of the colon (41\%) from the first study with EC [5] was confirmed, as well the presence of many adenomas $5 \mathrm{~mm}$ or smaller adenomas in the colon ascendens. The PDR and ADR in our study ( $72 \%$ and $47 \%$, respectively) were higher than those in two preceding studies $[5,6]$. Considering all adenomas and hyperplastic polyps above the sigmoid, we recommended that nearly $60 \%$ of our patients repeat an endoscopic follow-up according to the existing Swiss guidelines [9]. In comparison with the Swiss screening population $(\mathrm{n}=1912)$ undergoing standard colonoscopy, we improved the ADR with EC from 19.5\% to $47 \%$ and the PDR from $27 \%$ to $72 \%$ [10]. These excellent results, com- 


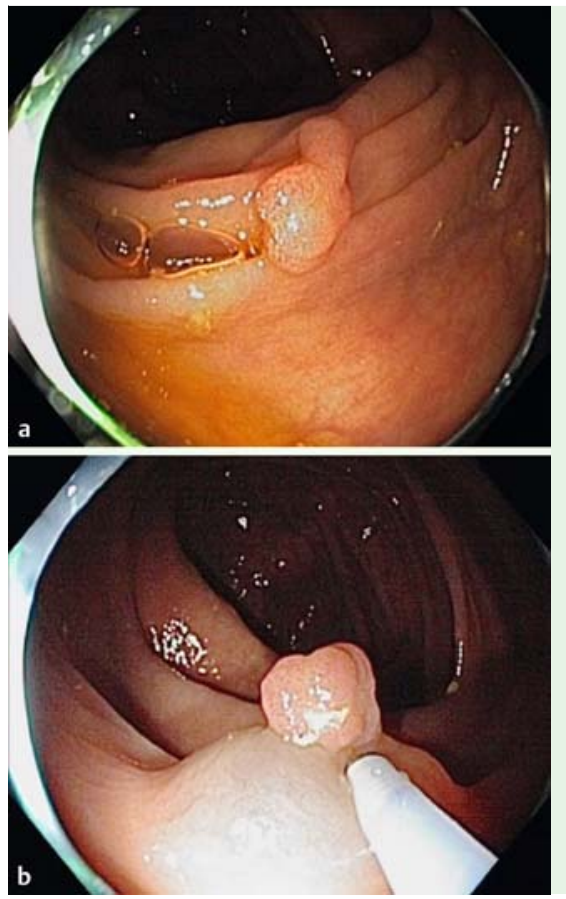

Fig. 2 a Colon ascendens with polyp (Paris classification Ip). b Lifting sign after injection.

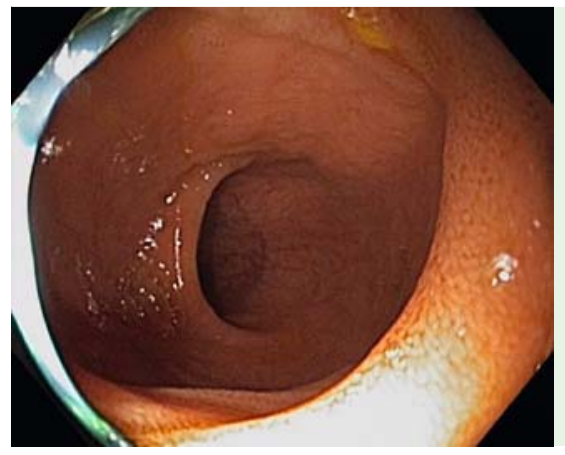

Fig.3 Terminal ileum.

\section{Summary}

\section{$\nabla$}

EC is feasible with the most commonly available colonoscopes without severe adverse events but with an excellent ADR, including small adenomas in the right side of the colon. Therefore, this technique may be recommended in the future to increase the ADR in a screening population.

\section{Competing interests: None}

\section{References}

1 Adler $A$, Wegscheider $K$, Lieberman $D$ et al. Factors determining the quality of screening colonoscopy: a prospective study on adenoma detection rates, from 12,134 examinations (Berlin colonoscopy project 3 , BECOP-3). Gut 2013; 62: 236-241

pared with the targeted ADR of at least 20\% [11], raise the question of whether the advised ADR should be adjusted.

Results can be significantly influenced by bowel preparation, endoscopic education, and examiner motivation (with EC as a new tool). Therefore, prospective crossover studies are needed. Finally, the higher incidence of polyps in our study may have been due to a higher level of susceptibility in our study population (one-third of the patients had first-degree relatives with CRC).

EC was safe for screening, even in the patients with diverticulosis (44\%, extensive diverticulosis in $6.7 \%$ ). We noted no perforation or other serious adverse events. EC could be a disadvantage in patients with severe diverticulosis because of the slightly greater challenges encountered in proceeding through the sigmoid colon (one failure in our study). During the follow-up of 4 to 12 weeks, we documented five mild adverse events ( Table5). Only one case of mild anal fissure was clearly attributed to EC. The two cases of mild diverticulitis may have also been induced by standard colonoscopy. Rectal bleeding was certainly due to rectal polypectomy.

Recently, many studies have aimed to achieve a better ADR. The results of cap-assisted colonoscopy have been controversial [12]. A new full-spectrum colonoscopy technique (FUSE) is promising [13], but the acquisition costs, with the need to change the endoscopes, are significant. Therefore, as a simple attachment to the distal tip of the colonoscope, the Endocuff seems to be a good and inexpensive alternative for increasing the ADR without restricting the field of vision ( $\bullet$ Fig. 2, $\bullet$ Fig. 3). The benefit of EC is that it is a safe measure that improves PDR and ADR in a screening population with no severe adverse events, even in patients with diverticulosis. The cecal intubation time is not lengthened. Ileal intubation is possible in a majority of patients. Inversion in the rectum seems to be no problem. Subjectively, we had better fixation of the colonoscopy in the hepatic and splenic flexures and better retraction of the haustral folds, especially in the right side of the colon and in the sigmoid colon. A significant number of small polyps were detected in the right side of the colon.
2 van Rijn JC, Reitsma JB, Stoker J et al. Polyp miss rate determined by tandem colonoscopy: a systematic review. Am J Gastroenterol 2006; 101: $343-350$

3 Corley DA, Jensen CD, Marks AR et al. Adenoma detection rate and risk of colorectal cancer and death. N Engl J Med 2014; 370: 1298-1306

4 Dik VK, Moons LM, Siersema PD et al. Endoscopic innovations to increase the adenoma detection rate during colonoscopy. World J Gas-

5 Lenze F, Beyna T, Lenz P et al. Endocuff-assisted colonoscopy: a new accessory to improve adenoma detection rate? Technical aspects and first clinical experiences Endoscopy 2014; 46: 610-614

6 Biecker E, Floer M, Heinecke A et al. Novel Endocuff-assisted colonoscopy significantly increases the polyp detection rate: a randomized controlled trial. J Clin Gastroenterol Epub 2014 Jun 11

7 Rembacken B, Hassan C, Riemann JF et al. Quality in screening colonoscopy: position statement of the European Society of Gastrointestinal Endoscopy (ESGE). Endoscopy 2012; 44: 957-968

8 Lee TJ, Blanks RG, Rees CJ et al. Longer mean colonoscopy withdrawal time is associated with increased adenoma detection: evidence from the Bowel Cancer Screening Programme in England. Endoscopy 2013; 45: $20-26$

9 Criblez D. Schweizer Gesellschaft für Gastroenterologie (SGGSSG). Konsensus-Empfehlung zur Nachsorge nach koloskopischer Polypek-

10 Marbet UA, Bauerfeind P, Brunner J et al. Colonoscopy is the preferred colorectal cancer screening method in a population-based program. Endoscopy 2008; 40: 650-655

11 Kaminski MF, Regula J, Kraszewska E et al. Quality indicators for colonoscopy and the risk of interval cancer. N Engl J Med 2010; 362: $1795-1803$

12 Westwood DA, Alexakis N, Connor SJ et al. Transparent cap-assisted colonoscopy versus standard adult colonoscopy: a systematic review and meta-analysis. Dis Colon Rectum 2012; 55: 218 - 225

13 Gralnek IM, Siersema PD, Halpern Z et al. Standard forward-viewing colonoscopy versus full-spectrum endoscopy: an international, multicentre, randomised, tandem colonoscopy trial. Lancet Oncol 2014; 15: $353-360$ troenterol 2014; 20: 2200-2211 tomie. Schweiz Med Forum 2007; 7: 994 -999 